\title{
'It takes two': men and contraception
}

Toni Belfield

\section{Background}

Worldwide, a woman dies every minute as a result of pregnancy. Each year, around 80 million women face unwanted or unplanned pregnancy. Of these, 20 million will risk unsafe abortion and 68000 will die. ${ }^{1}$ Add the consequences of untreated sexually transmitted infections (STIs) and the scenario is even worse. Shocking or what? Having sex and becoming pregnant takes two - it's not just a woman thing. Men are involved.

Women have always carried the responsibility for reproductive health, morbidity and mortality. However, decisions around the use of contraception for centuries relied entirely on men - withdrawal, periodic abstinence and use of condoms and their precursors cannot be used without the co-operation of men. The advent of modern methods of contraception in the mid-20th century - oral contraception ('the pill'), intrauterine contraceptive devices and improved methods of sterilisation - for the first time provided women in developed countries with reliable and safe contraception. Not only did the use of these methods essentially absolve men from contraceptive decisions, contraception became independent of intercourse. These factors altered the balance of male-female involvement in contraception and contributed significantly to women's reproductive emancipation, while decreasing men's visibility in contraception and reproductive health.

However, sex still takes two and things are changing. There is increasing awareness that men should and need to be properly involved in sexual and reproductive health. Not just as a support to women's needs, but also with regard to their own needs. This view has been strengthened by the increasingly high rates of unplanned pregnancy and STIs, including HIV, where men are expected to be involved in 'safer sex' and have a role in reproductive health and childrearing decision making. The imminent introduction of hormonal contraception for men means that they can no longer be left out of the contraceptive equation.

\section{Men's involvement and role}

So how do we support men to become more aware and involved in sexual health issues? How do we support men in accessing services? Importantly, how do we improve services so that men want to use them? The Men's Health Forum, which constantly campaigns for a gender-specific approach to health care, states: "Men's health is poor, and in many ways getting poorer. Prostate disease - both benign and malignant - is becoming more common, the incidence of testicular cancer continues to rise, sexually transmitted infection rates are up, sexual dysfunction (such as erectile problems and premature ejaculation) continue to affect large numbers of men". In their report, Private Parts,

J Fam Plann Reprod Health Care 2005; 31(1): 3-5

fpa, London, UK

Toni Belfield, BSc, FRSH, Director of Information

Correspondence to: Toni Belfield, fpa, 2-12 Pentonville Road, London N1 9FP, UK. E-mail: tonib@fpa.org.uk
Public Policy - Improving Men's Sexual Health, ${ }^{2}$ they argue that sexual health policies and services have largely failed to take men's specific experiences and needs into account. They are critical of The National Strategy for Sexual Health and $H I V^{3}$ as it pays limited attention to men. They call for family planning clinics (FPCs), which are seen as women-only services, to become more malefriendly.

The shortcomings of family planning services in attracting men have already been documented more than 23 years ago in the then British Journal of Family Planning when Howard and Whittaker highlighted the difficulties men experienced in obtaining condoms from FPCs. ${ }^{4} \mathrm{~A}$ report by the Birth Control Trust and Family Planning Association in $1984^{5}$ confirmed that the provision of condoms in clinics was poor and that clinic staff were worried that having men in family planning settings would 'intimidate women and staff would leave'. The Family Planning Association's 'Men Too' campaign in the mid1980s was born out of the recognition that men received less support and encouragement than women. Although women had fought long and hard to have control over their own fertility and decide on the number of children they wanted, it was realised that conception, parenthood and childrearing were areas in which men wanted more involvement. Improving male involvement does not mean men having a monopoly on decision making, but rather highlights the need to re-examine the balance between the needs of women and men. Research during the 1990s resulted in articles, reports and recommendations, but improvements in service delivery for men have been slow. Today, apart from genitourinary medicine services, men are minority users of sexual health services, and the numbers using FPCs are still tiny. In England, only 106000 men visited FPCs compared to 1.2 million women between 2003 and $2004 .{ }^{6}$ Few men visit general practice, least of all for anything to do with sexual health. "It is surely the last straw if the government intends to insult us by filling up our surgeries with lots of louts queuing up for the issue of condoms." An extract from a general practitioner (GP)'s letter to the British Medical Journal in 1975 may have influenced a decision made at the British Medical Association's annual representative meeting that year, that GPs should not prescribe condoms as part of the newly negotiated, free, family planning service. This created a major anomaly in contraceptive provision in general practice, which remains an anomaly today. ${ }^{7}$

The publication in 2001 of The National Strategy for Sexual Health and HIV $V^{3}$ confirmed that sexual health and physical health are interrelated and that essential elements of good sexual health are equitable relationships with access to information and services to avoid the risks of unintended pregnancy, illness and disease. This strategy provides continued opportunity to address how we support men in the area of contraception as part of a holistic approach to sexual health.

"Improved contraceptive choice for men in the near future represents a significant advance in the emancipation of both sexes. Unless, however, family planning services cease to remain a virtual 'no man's land', the burden of responsibility for contraception will continue to remain firmly on the shoulders of women." (Ian Banks, Men's Health Forum, October 2004) 


\section{Male hormonal contraception}

Any mention of male hormonal contraception brings out the sceptics: 'it will never happen', 'men won't want to use it' and 'women won't trust a man to use it'. Shame on you if you hold such views. One can have some sympathy with the first point - media headlines have been suggesting the imminent availability of 'the male pill' for the last 35 years. Finding a method that effectively blocks the production of sperm, and is easily reversible and safe with no major side effects, was always going to take time. The human male has a highly organised 'conveyor belt' production of sperm that is more complex to interrupt than a woman's cyclical pattern of ovulation. However, over 30 years of research have resulted in three hormonal contraceptive methods for men: a pill, implants and an injection. Human trials using progestogens and testosterone have shown them to be highly effective with few side effects. Why three different methods? Just as women have a number of different choices, so it is vital that men do too. 'Do men want to use it?' The answer is yes. Research shows clearly that many men would like to take some contraceptive responsibility and would use a hormonal method if it were available. ${ }^{8}$ The myth about women 'not trusting a man to use it' is just that - a myth, not fact. ${ }^{9}$ It's a nonsense to suggest that men somehow cannot be trusted to use contraception well women already 'trust' men to use condoms, women themselves use contraception both well and badly - men will be no different. Contraceptive decision making and use are complex; the introduction of new male contraceptive methods that extend choice, are reversible and nonintercourse-related raise the same questions and issues about safety, effectiveness and adherence that women have been addressing for years.

\section{The future}

Hormonal contraception for men will be a reality within the next 10 years. Professionals providing contraceptive services need to address what is required now to include and support men making contraceptive choices.
"It will be a great challenge and opportunity for providers to really engage with men and offer a truly comprehensive family planning service providing the full range of choices available." (Richard Anderson, Medical Research Council Human Reproductive Sciences Unit, Centre for Reproductive Biology, Edinburgh, UK)

Men are definitely on the agenda - even the women's magazine Cosmopolitan, intrinsically linked with women's sexual liberation, is trying to redress the balance by having more male contributors. Why? To give female readers an insight into "what they're thinking, what they want". 10 If Cosmopolitan can do it - so can we!

Statements on funding and competing interests

Funding. None identified.

Competing interests. None identified.

References

1 World Health Organization (WHO). Unsafe Abortion - Global and Regional Estimates of the Incidence of Unsafe Abortion and Associated Mortality in 2000. Geneva, Switzerland: WHO, 2004.

2 Men's Health Forum. Private Parts, Public Policy: Improving Men's Sexual Health. London, UK: Men's Health Forum, 2003. http://www.menshealthforum.org.uk/uploaded_files/mhfprivateparts. pdf.

3 Department of Health. The National Strategy for Sexual Health and HIV. London, UK: Department of Health, 2001.

4 Howard G, Whittaker I. Difficulties in obtaining condoms in the NHS. Br J Fam Plann 1981; 2: 12-15.

5 Birth Control Trust, Family Planning Association. Men, Sex and Contraception. London, UK: Birth Control Trust, 1984.

6 Department of Health Statistical Bulletin. NHS Contraceptive Services, England: 2003-4. London, UK: Department of Health, 2004.

7 Belfield T. A call for condoms on the FP10. MIMS Mag 1989; 1 Dec: 51.

8 Martin CW, Anderson RA, Cheng L, Ho PC, van der Spuy Z, Smith $\mathrm{KB}$, et al. Potential impact of hormonal male contraception: crosscultural implications for development of novel preparations. Hum Reprod 2000; 15: 637-645.

9 Glasier AF, Anakwe R, Everington D, Martin CW, van der Spuy Z, Cheng L, et al. Would women trust their partners to use a male pill? Hum Reprod 2000; 15: 646-649.

10 Byrne C. Sex and frocks and reader's real lives. The Independent, 25 October 2004.

\section{HOW TO REGISTER FOR ACCESS TO THE ELECTRONIC JOURNAL}

\section{Registration Process}

1. On connecting with the Faculty website (www.ffprhc.org.uk), click on the picture of the 'Journal' to access the electronic Journal.

2. Next, under Related Links, click on 'Faculty Membership Activation'.

3. In the appropriate boxes enter your Surname, E-mail Address, Country and Membership Number (M000, D000, etc - six digits). NB. These boxes are case-sensitive.

4. Next, select a User Name and Password.

5. Ignore the box marked 'Ingenta Select ID number - CID'.

6. Click on 'Enable Access'.

7. A confirmation e-mail will be sent to you.

\section{After Registration}

Once you have registered you can access the Journal as follows:

1. On connecting with the Faculty website (www.ffprhc.org.uk), click on the picture of the 'Journal' to access the electronic Journal.

2. Select the volume and issue number.

3. Select the article you wish to view.

4. Enter your user name and password. 